\title{
Clinical significance of "circulating fibrin monomers"
}

\author{
EM HASELAGER, J VREEKEN
}

\begin{abstract}
From the Department of Internal Medicine, University Hospital "Wilhelmina Gasthuis", Amsterdam, The Netherlands
\end{abstract}

SUMMARY During the decade 1970-9 we investigated circulating fibrin monomers in 3293 patients Fibrinaemia was determined by means of the ethanol gelation test (EGT). This was positive in 148 patients $(4.5 \%)$ and was highly correlated with fibrogenal fibrin products. In many diseases the tesi was only transiently positive (1 or 2 days). However in patients with circulating fibrin monomersir demonstrable for more than 5 days (chronic fibrinaemia) malignant disease was associated in $63 \%$ Chronic fibrinaemia occasionally preceded overt malignancy by a long period. Overall, only $10 \cdot 8 \%$ of patients with malignant disease showed chronic fibrinaemia. The clinical symptoms most often. associated with chronic fibrinaemia were those of venous thrombosis $(42 \cdot 8 \%)$ and abnormal bleeding $(10.7 \%)$. Thromboembolism in the absence of malignant disease only occasionally showed shor term positive EGT and chronic fibrinaemia was never seen. Almost half (46.5\%) of patients wit chronic fibrinaemia had neither thromboembolic disease nor a haemorrhagic diathesis.

The presence of thrombin-induced fibrinogen derivatives in the blood is considered by some authors to be a sign of hypercoagulability of the plasma. ${ }^{1-6}$ Fibrin monomers are known to form complexes with fibrinogen and fibrinogen degradation products (FDP/fdp), giving rise to high molecular weight complexes which are initially soluble. ${ }^{2}$ ? When such complex formation occurs in the blood, a condition tentatively termed fibrinaemia is present. ${ }^{8}$ These complexes may be cleared by the reticuloendothelial system (RES) or deposited either diffusely (diffuse intravascular coagulation) or locally (local thrombosis). ${ }^{9-11}$ Fibrin monomers can be detected by several laboratory methods which vary in laboriousness and sensitivity. ${ }^{1}$ 12-15

The clinical usefulness of a laboratory test in large numbers of patients is improved when, while remaining reliable, it is easy to perform. The ethanol gelation test (EGT) for the detection of circulating fibrin monomers, introduced by Godal and Abildgard, ${ }^{1}$ fulfills these two criteria; however its sensitivity is limited because it only becomes positive when $2 \cdot 4-3 \cdot 8 \%$ plasma fibrinogen is circulating in the form of fibrin monomers. ${ }^{16}$ Using this test, fibrin monomer complexes have been detected in several diseases known to be associated with intravascular fibrin formation. ${ }^{3} 812$ Although one study has evaluated this test in a large number of hospital patients on admission, ${ }^{17}$ the clinical signi-

Accepted for publication 6 October 1980 ficance of prolonged circulation of fibrin monome remains obscure.

In order to define the clinical value of the EG we have performed this test in about one third of alf patients admitted to our Department of Interna Medicine between 1970 and 1979 . In a substantiâ number of these patients the test was frequent repeated to establish the effect of treatment and the course of the disease on the outcome of the test. The presence of a positive EGT was defined as fibrioaemia. We were especially interested in the signits cance of "chronic fibrinaemia" in its relation thrombotic and haemorrhagic conditions and in the effect of antithrombotic drugs on the presence of fibrin monomers in vivo. In addition we have correlated the outcome of the EGT with fibrinoge levels and the level of FDP/fdp.

\section{Materials and methods}

PATIENTS

In the initial phase of the study, we performed the EGT in patients with all kinds of diseases admitted to the Department of Internal Medicine. In the last part of the study we were especially interested in patients with malignancy or suspected malignances, thromboembolism, haemorrhagic diathesis, sep caemia, and liver disease.

The diagnosis of malignancy was in most cases confirmed by histological examination. Septicaem was confirmed by positive blood cultures. The 
clinical diagnosis of liver cirrhosis was confirmed by liver biopsy. Venous thromboembolism was usually diagnosed by clinical examination but included in the study was a group of 37 patients with established venous thromboembolism, which has been described previously together with diagnostic criteria.18 We performed the EGT in 3293 patients, $37.3 \%$ of those admitted to our Department.

\section{BLOOD SAMPLING}

Blood was collected by venipuncture: nine volumes of venous blood were mixed as soon as possible with one volume of $3.8 \%$ trisodium citrate solution. The plasma was separated from the cells by centrifugation for $10 \mathrm{~min}$ at $1260 \mathrm{~g}$ at room temperature.

THE ETHANOL GELATION TEST

The EGT was performed according to Godal and Abildgard. ${ }^{1}$ In brief: $0.5 \mathrm{ml}$ plasma was mixed with $0.5 \mathrm{ml} 50 \%$ ethanol and was left undisturbed at room temperature for exactly 10 minutes. It was then examined for gel formation by gently tilting the tube. Only when clear gel formation occurred, was the test considered positive. When only precipitation or change of opacity occurred in the absence of gel formation, the test was considered to be negative.

Although the results of a single determination are included in the results, the final analysis only refers to those patients for whom the test was positive on at least two occasions, necessitated as a check against false positive tests arising from a technically poor venipuncture.

\section{FIBRINOGEN}

Fibrinogen was determined as described by Strengers and Asberg. ${ }^{19}$ Normal value: $200-400 \mathrm{mg} / 100 \mathrm{ml}$.

\section{FIBRINOGEN/FIBRIN DEGRADATION}

PRODUCTS (FDP/fdp)

FDP/fdp were determined by the method described by Laurell. ${ }^{20}$ Four $\mathrm{ml}$ blood were collected into $0.04 \mathrm{ml}$ aprotinine (Transylol: $100000 \mathrm{KIU} / \mathrm{ml}$ ) and kept at $37^{\circ} \mathrm{C}$ for 2 hours, after which it was centrifuged for $10 \mathrm{~min}$ at $1260 \mathrm{~g}$. One ml of the supernatant serum was incubated with $20 \mathrm{U}$ thrombin at $37^{\circ} \mathrm{C}$ for 15 $\mathrm{min}$ and then centrifuged for $15 \mathrm{~min}$ at $1260 \mathrm{~g}$. The samples were stored at $-20^{\circ} \mathrm{C}$ until testing. All normal subjects had a level below $1.5 \mathrm{mg} / 100 \mathrm{ml}$ serum.

\section{THROMBIN}

Thrombin (Topostasin, Roche, Basle) was dissolved in saline $(0.9 \% \mathrm{NaCl})$ to a final concentration of $500 \mathrm{U} / \mathrm{ml}$. Freshly prepared thrombin solution was used.

\section{Results}

Between 1970 and 1979 we performed the EGT on 6782 occasions in a total of 3293 patients with various diseases. In 149 of these $(4.5 \%)$ the test was positive at least once. Since the detection of a positive EGT prompted further investigations, it was possible to determine the duration of this abnormality. As is shown in Table 1 the test was positive for only one day in 83 patients, for two to five days in 21 patients and for more than five days in 45 patients. The longest positive EGT was followed for five years.

Table 1 Duration of the positive ethanol gelation test in 149 patients

\begin{tabular}{|c|c|c|c|c|}
\hline \multirow[t]{2}{*}{ Duration } & \multicolumn{3}{|c|}{ Ethanol gelation test } & \multirow[t]{2}{*}{ Total } \\
\hline & Positive once & Positive twice & $\begin{array}{l}\text { Positive more } \\
\text { than twice }\end{array}$ & \\
\hline One day & 57 & 16 & 10 & 83 \\
\hline Two days & & 7 & 5 & \\
\hline Three days & & & 3 & \\
\hline Four days & & & 3 & 21 \\
\hline Five days & & 1 & 2 & \\
\hline $\begin{array}{l}\text { Six days } \\
>\text { six days }\end{array}$ & & 1 & $\begin{array}{r}3 \\
41\end{array}$ & 45 \\
\hline Total & 57 & 25 & 67 & \\
\hline
\end{tabular}

CLINICAL DIAGNOSIS

The data in Table 2 demonstrate that a large variety of disorders may be associated with a positive EGT. It appears that short-term fibrinaemia is found mostly in patients with acute diseases including septicaemia, bacterial meningitis, abruptio placentae and dissecting aortic aneurysm. In 10 out of 60 patients, malignant disease was associated with short-term fibrinaemia. Of the 44 patients with chronic fibrinaemia, $28(63.6 \%)$ had a malignancy and 12 of these presented with venous thromboembolism. In one patient the EGT was positive for four years before a tumour became apparent. The malignancies most often associated with chronic fibrinaemia were carcinomas of the pancreas, gall bladder, prostate, and bronchus (Table 3).

\section{THROMBOHAEMORRHAGIC CONDITIONS, FDP/fdp AND FIBRINAEMIA}

Thirty-seven patients had established venous thromboembolism, but without malignancy, fibrinaemia was detected in only two of these and this was short-term and never a chronic phenomenon. The most prominent clinical symptom of chronic fibrinaemia was venous thromboembolism (Tables 2 and 4). In patients with malignancy and chronic fibrinaemia, a haemorrhagic diathesis was present only occasionally and in about half of such patients thrombohaemorrhagic symptoms were absent (Table 
Table 2 Associated diseases in patients showing a positive ethanol gelation test

\begin{tabular}{|c|c|c|c|c|c|}
\hline & \multicolumn{5}{|l|}{ Patients } \\
\hline & \multicolumn{2}{|l|}{$\begin{array}{l}\text { EGT } \\
\text { Positive once }\end{array}$} & \multicolumn{2}{|l|}{$\begin{array}{l}\text { EGT } \\
\text { Positive twice }\end{array}$} & \multirow{2}{*}{$\begin{array}{l}\text { EGT } \\
\text { Positive more } \\
\text { than five days }\end{array}$} \\
\hline & Tested once & $\begin{array}{l}\text { Tested more } \\
\text { than once }\end{array}$ & Tested twice & $\begin{array}{l}\text { Tested more } \\
\text { than twice }\end{array}$ & \\
\hline Sepsis (gram negative) & 1 & 3 & 1 & & 2 \\
\hline Malignancy without thromboembolism & $3^{2}$ & 5 & & 3 & 13 \\
\hline Malignancy with thromboembolism & & 2 & & & 12 \\
\hline Malignancy with haemorrhagic diathesis & 1 & & & & 3 \\
\hline $\begin{array}{l}\text { Venous thromboembolism without malignancy } \\
\text { Heroine addict with diffuse intravascular coagulation (DIC) }\end{array}$ & 2 & 5 & & 3 & $4^{8}$ \\
\hline $\begin{array}{l}\text { Meningitis (bacterial) } \\
\text { Mense intravascular coagulation (DIC) }\end{array}$ & & $\begin{array}{l}1 \\
4\end{array}$ & & 3 & \\
\hline Abruptio placentae & & & & 1 & \\
\hline Liver cirrhosis & 1 & 4 & & 3 & 3 \\
\hline Aneurysm cardiac & & & & 1 & \\
\hline aortic dissecting & $2^{2}$ & 1 & 1 & 3 & \\
\hline Nephrotic syndrome & & & & & 1 \\
\hline Leukaemia & 1 & & & & 3 \\
\hline Autoimmunohaemolytic anaemia and DIC & & & & & 1 \\
\hline Unknown & 5 & 5 & 2 & & 2 \\
\hline Miscellaneous & $2^{4}$ & $10^{5}$ & $1^{6}$ & $3^{7}$ & \\
\hline
\end{tabular}

${ }^{1}$ The test was initially positive but negative when repeated.

'One patient had a dissecting aortic aneurysm and lung cancer.

'One patient had a venous thromboembolism with sepsis.

'Intoxication with analgesic drugs, bleeding ulcer with shock.

'Leptospirosis, vasculitis, diabetic coma, Guillain-Barré syndrome, haemolytic anaemia, pneumonia, malaria, Marfan's syndrome, emphysema, infected delivery.

Myocardial infarction.

7Vasculitis, ulcerative colitis, tuberculosis.

Table 3 Patients with chronic fibrinaemia and associated malignancy

Carcinoma of the pancreas or gallbladder

Prostatic carcinoma

Bronchial carcinoma

Carcinoma of the stomach

Seminoma

Carcinoma of the breast

Carcinoma of indeterminate site

Total

4). 125I-fibrinogen was injected in 3 of these patients to find out if subclinical thrombosis was present. Leg scanning in these patients was negative, but the in vivo half-life of the injected 125 I-fibrinogen was shortened (mean value: $28 \mathrm{~h}$, normal: 4-5 days). Arterial thrombi were not seen in patients with chronic fibrinaemia.

Thromboembolism was found in malignancy without chronic fibrinaemia in 11 of 231 patients $(4 \cdot 7 \%)$. The serum FDP/fdp level was determined in 115 patients with malignancy and a negative EGT. The FDP/fdp level was less than $2 \mathrm{mg} / 100 \mathrm{ml}$ in 57

Table 4 Thrombohaemorrhagic disease associated with malignancy and chronic fibrinaemia in 28 patients

Thromboembolism

Haemorrhagic diathesis

Neither of these conditions of these patients. Three of these showed clinical thromboembolism $(5 \cdot 2 \%)$. In the residual 58 patientso $\overrightarrow{\vec{B}}$ the serum FDP/fdp level was $2 \mathrm{mg} / 100 \mathrm{ml}$ or more and eight of these showed clinical thromboembolism $(13.7 \%)$. Thirty-seven patients had established? venous thromboembolism, but without malignancy, fibrinaemia was detected in only two of these and: this was short-term and never a chronic phenom- 3 enon.

RELATION BETWEEN FIBRINOGEN, FDP/fdp AND FIBRINAEMIA

The distribution of fibrinaemia at various fibrinogeno levels is shown in Table 5. The majority of patients with fibrinaemia had a fibrinogen level between $50 \mathrm{or}$ and $500 \mathrm{mg} / 100 \mathrm{ml}$; at fibrinogen concentrations of more than $500 \mathrm{mg} / 100 \mathrm{ml}$ the incidence of a positive N

Table 5 Fibrinogen levels correlated with a positive ethanol gelation test

\begin{tabular}{|c|c|c|c|}
\hline \multirow{2}{*}{$\begin{array}{l}\text { Fibrinogen level } \\
(\mathrm{mg} / 100 \mathrm{ml})\end{array}$} & \multicolumn{2}{|l|}{ Patients } & \multirow[t]{2}{*}{$\%$} \\
\hline & Total number & Positive EGT & \\
\hline $\begin{array}{l}50 \\
50-150 \\
150-500 \\
500-600 \\
600\end{array}$ & $\begin{array}{r}3 \\
186 \\
3488 \\
421 \\
381\end{array}$ & $\begin{array}{r}1 \\
58 \\
362 \\
20 \\
20\end{array}$ & $\begin{array}{r}33 \cdot 3 \\
31 \cdot 0 \\
10 \cdot 4 \\
4 \cdot 8 \\
5 \cdot 3\end{array}$ \\
\hline
\end{tabular}


EGT dropped. The level of FDP/fdp in serum exceeded $1.5 \mathrm{mg} / 100 \mathrm{ml}$ and was more than $2 \mathrm{mg} / 100$ $\mathrm{ml}$ in $97.3 \%$ and $93 \%$ respectively of all patients with a positive EGT (Table 6). The level of FDP/fdp in serum exceeded $1.5 \mathrm{mg} / 100 \mathrm{ml}$ and was more than $2 \mathrm{mg} / 100 \mathrm{ml}$ in $29 \%$ and $21 \%$ respectively of all patients with a negative EGT (Table 6). High fibrinogen levels do not exclude the possibility of a negative ethanol gelation test.

Table 6 Correlation between a positive or negative ethanol gelation test and an elevated level of FDP/fdp in serum

\begin{tabular}{lll}
\hline & EGT positive & EGT negative \\
\hline FDP $/ \mathrm{fdp} \geqslant 1 \frac{1}{2} \mathrm{mg} / 100 \mathrm{ml}$ & $97 \cdot 3 \%$ & $29 \%$ \\
FDP $/ \mathrm{fdp} \geqslant 2 \mathrm{mg} / 100 \mathrm{ml}$ & $93 \%$ & $21 \%$ \\
\hline
\end{tabular}

EFFECT OF TREATMENT ON CHRONIC FI B R IN AEM I A

In all patients with a positive EGT for more than 5 days, intravenous heparin administration at a dosage of $1500 \mathrm{U} / \mathrm{h}$ to $7500 \mathrm{U} / \mathrm{h}$ was followed by a negative EGT. When, instead of heparin, coumarin derivatives were administered, the EGT remained positive even when the prothrombin time was prolonged more than twice control value. In those patients whose positive EGT had become negative upon heparin administration (except in one patient), coumarin derivatives failed to maintain a negative EGT.

In some patients with prostatic carcinoma, it was possible to evaluate the effect of hormonal treatment. These patients showed a negative EGT after induction of a remission by hormonal treatment. A negative EGT became positive again when heparin treatment was discontinued, except in patients with prostatic carcinoma who responded to hormonal treatment. Two patients "escaped" hormonal treatment for prostatic carcinoma. In one there was a reappearance of the fibrinaemia after a few months. Fibrinaemia did not reappear in the second patient even after several years.

\section{Discussion}

The aim of the present study was to define the clinical significance of fibrin monomers as detected by the EGT. Short-term fibrinaemia was found to be present in a number of patients with acute disorders such as septicaemia, abruptio placentae, dissecting aortic aneurysm and venous thromboembolism (Table 2). Since anticoagulant (heparin) treatment was instituted in patients with venous thromboembolism shortly after diagnosis, it is reasonable to suppose that such treatment could have influenced fibrinaemia. One might expect, however, when the EGT is repeated after withdrawal of heparin treatment, to see the EGT become positive again when the thrombin producing process is still operative.

Long-term fibrinaemia was found most often in patients with malignancy. Chronic fibrinaemia may be present before the malignant process is diagnosed. In one of our patients with chronic fibrinaemia, repeated examinations during a 4 year follow-up period failed to detect malignancy; finally, after this period, a non-Hodgkin's lymphoma was found. Peuscher et al., ${ }^{18}$ have reported that fibrinopeptide A (a peptide cleaved from the fibrinogen molecule by thrombin) or the in vitro generation of fibrinopeptide $\mathrm{A}$ or both, are often increased in patients with metastatic malignancy, indicating that local or systemic thrombin is present.

Several mechanisms have been postulated to explain how activation of blood coagulation and fibrin formation in such cancer patients may proceed. Among the activating substances are: tumour-derived thromboplastin-like material, ${ }^{21-23}$ proteolytic enzymes ${ }^{24} 25$ and platelet factors. ${ }^{26-28}$ In addition penetration of the malignant process in the vessel wall may be responsible for activation of blood coagulation in some patients. ${ }^{29}$ It is intriguing that circulating monomer complexes may be present for such a long period without giving detectable organ damage, for example, in the kidney or lungs. Apparently they are completely soluble and defence systems, such as fibrinolysis, are stimulated to prevent systemic fibrin deposition. The increased level of FDP/fdp in almost all patients with fibrinaemia reflects augmented fibrinolysis. It is far from clear whether or not coagulation (formation of a fibrin net) is present in patients with chronic fibrinaemia. So chronic diffuse intravascular coagulation does not seem to be an appropriate description for all these conditions. Since $42.8 \%$ of patients with chronic fibrinaemia suffered from venous thrombosis or pulmonary embolism, the question arises as to whether fibrin monomers can also be only a result of thrombosis. Therefore we studied 37 patients with established thromboembolism, but without malignancy. None of them had chronic fibrinaemia. Besides that, we found no local signs of thrombosis in three patients with chronic fibrinaemia by ${ }^{125}$ I-fibrinogen leg scanning.

It has been reported that almost $50 \%$ of the patients in which the EGT is positive display an increased fibrinogen level $(>500 \mathrm{mg} / 100 \mathrm{ml}) .{ }^{1617}$ This is not in agreement with our results.

The effect of anticoagulant treatment on fibrinaemia was not uniform. In all patients the EGT became negative upon heparin treatment although 
the dosage required varied widely. It appears most logical to relate the effect of heparin to its inhibitory action on activated coagulation factors $\left(X_{a}\right)$ and thrombin through antithrombin III. When instead of heparin, coumarin derivatives were used, chronic fibrinaemia persisted despite adequate prolongation of the prothrombin time.

\section{References}

${ }^{1}$ Godal HC, Abildgard U. Gelation of soluble fibrin in plasma by ethanol. Scand J Haematol 1966;342:342-50.

${ }^{2}$ Lipinski B, Wegrzynowixcz Z, Budzynski AZ. Soluble unclottable complexes formed in the presence of fibrinogen degradation products (FDP) during the fibrinogen-fibrin conversion and their potential significance in pathology. Thromb Haemost 1967;65:65-77.

${ }^{3}$ Kierulf $\mathrm{P}$, Godal HC. Fibrinaemia in medical patients screened by the ethanol gelation test. Acta Med Scand $1971 ; 190: 185-90$.

${ }^{4}$ Niewiarowski S, Gurewich V. Laboratory identification of intravascular coagulation. The serial dilution of intravascular coagulation. The serial dilution protamine sulphate test for the detection of fibrin monomers and fibrin degradation products. J Lab Clin Med 1971;77: 665-76.

${ }^{5}$ Müller-Berghaus G, Hocke M. Effect of endotoxin on the formation of microthrombi from circulating fibrin monomer complexes in the absence of thrombin generation. Thromb Res 1971;1:541-8.

${ }^{6}$ Graeff $\mathrm{H}$, Von Hugo R, Hafter R. In vivo formation of soluble fibrin monomer complexes in human plasma. Thromb Res 1973;3:465-76.

7 Sherman LA. Fibrinogen turnover: Demonstuation of multiple pathway of catabolism. J Lab Clin Med 1972; 79:710-23.

${ }^{*}$ Vreeken J, Van Aken WG. Chronic fibrinaemia as an indicator of a "prethrombotic state". Neth J Med 1974; 17:121-30

9 Müller-Berghaus G, Heirich D. Fibrin monomer and platelet aggregation in vitro and in vivo. Br J Haematol 1972;23:177-88.

${ }^{10}$ Müller-Berghaus G, Roka J, Lasch HG. Induction of glomerular microclot formation by fibrin monomer infusion. Thromb Haemost 1973;29:375-83.

11 Lipinski B, Gurewich V, Nowak A. The effect of heparin and dipyridamole on the deposition of fibrin-like material in rabbits infused with soluble fibrin monomer of fibrinogen. Thromb Res 1974;5:343-58.

12 Breen FA Jr, Tullis JL. Ethanol gelation: a rapid screening test for intravascular coagulation. Ann Intern Med 1968 69:1197-206.

${ }^{13}$ Kisker CT, Rush R. Detection of intravascular coagulation. J Clin Invest 1971;50:2235-41.

1 Fletcher AP, Alkjaersig N. Blood hypercoagulability and thrombosis. Clin Res 1970;18:531.

${ }^{15} \mathrm{Kierulf} \mathrm{P}$. Studies on soluble fibrin in plasma III. N terminal analysis of a modified fraction I (Cohn) fromes plasmin- and thrombin-incubated plasma. Scand J Clin Lab Invest 1973;31:43-9.

${ }^{16}$ Reiniche R. Matthias FR, Lasch HG. Content of soluble infarction, with carcinomas and consumption coagulo $\frac{\omega}{7}$ pathy. Thromb Res 1977;11:365-75.

17 Slaastad RA, Godal HC. Coagulation profile and the ethanol gelation test with special reference to comes ponents consumed during coagulation. Scand J Haematot 1976:16:32-7.

${ }^{18}$ Peuscher FW. The significance of fibrinopeptide $\mathrm{A}$ patients with cancer and venous thromboembolism Thesis. Amsterdam, 1980.

19. Strengers TH, Asberg EGM. Een screeningtest, gevolgto door een snelle kwantitatieve microbepaling vancw fibrinogeen in plasma. Ned Tijdschr Geneeskd 1963;107 i 2044-5.

2" Laurell CB. Quantitative estimation of proteins hy electrophoresis in agarose gel containing antibodies. Anal Biochem 1966;15:45-52.

21 Lawrence EA, Bowman DE, Moore DB, Bernstein GI. Athromboplastic property of neoplasms. Surg ForunR 1952;3:694-8

${ }^{22} \mathrm{O}$ Meara RAQ. Coagulative properties of cancer. Ir J Me't Sci $1958 ; 394: 474$.

${ }^{23}$ O'Meara RAQ, Thornes RD. Some properties of the cancer coagulative factor. Ir J Med Sci 1961;423:106-12.

2 Pineo GF, Regoeczi E, Hatton MWC, Brain MC. The activation of coagulation by extracts of mucus: possible pathway of intravascular coagulation accom panying adenocarcinomas. J Lab Clin Med 1973:82: 255-66.

${ }^{25}$ Pineo GF, Brain MC, Gallus AS, et al. Tumors, mucu跤 production and hypercoagulability. Ann NY Acad Sc 1974;230:262-70.

${ }^{26}$ Miller SP, Sanchez-Avalos J, Stefanski T, et al. Coagulation disorders in cancer. I. Clinical and laboratory studies. Cancer 1967;20:1452-65.

27 Moolten SE, Vroman L, Vroman GMS, et al. Role of. blood platelets in thromboembolism. A.M.S. Arch Into Med 1949;84:667-710.

${ }^{28}$ Davis RB, Theologides A, Kennedy BJ. Comparative studies of blood coagulation and platelet aggregation irion patients with cancer and non-malignant diseases. Anı Intern Med 1969;71:67-80.

${ }^{29}$ Sproul EE. Carcinoma and venous thrombosis: theo frequency of association of carcinoma in the body of tail of the pancreas with multiple venous thrombosis Am J Cancer 1938;34:566-85.

Requests for reprints to: Dr EM Haselager, Departmen $\mathcal{O}$ of Internal Medicine, University Hospital "Wilhelminiw Gasthuis", Amsterdam, The Netherlands. 